\title{
EL MODELO TERRITORIAL DEL ESTADO EN ESPAÑA Y SUS PROBLEMAS ACTUALES
}

\section{Manuel ARAGÓN REYES ${ }^{1}$}

RESUMEN: Después de revisar el tratamiento que la doctrina española ha otorgado al modelo territorial del Estado Español (en especial las aportaciones de Juan José Solazábal), en el artículo se analiza, desde la doble perspectiva del derecho constitucional y la política constitucional, la situación actual del Estado autonómico. Se afirma la necesidad de aclarar y resolver de manera definitiva el modelo territorial español al tiempo que preservar su actual extensión territorial, para lo cual el autor expone las razones que llevan a excluir como opciones viables la confederación, el pacto con la corona y el derecho de autodeterminación. Como alternativa, el autor propone el Estado autonómico, modelo original, aún inacabado, que no sería igual al federal (con el cual carece de sentido sostener una distinción radical) ni al regional. El Estado autonómico permitiría una solución al problema territorial español, pues su flexibilidad y otras características admiten en mejor manera cierto grado de asimetría territorial y "una equilibrada integración entre dicha asimetría y la necesaria unidad estatal". En el artículo se analizan rigurosamente tanto las cuestiones teóricas como el procedimiento de reforma constitucional que podría llevar a la adopción plena del Estado autonómico en España.
ABSTRACT: After reviewing the treatment accorded by Spanish doctrine to the territorial model of the Spanish State (in particular the contributions of Juan José Solazábal), the article examines the present status of the autonomous State from the dual perspective of Constitutional law and Constitutional policy. The need is affirmed of formally clarifying and resolving the Spanish territorial model while, at the same time, preserving its present territorial size, for which purpose the author puts forward the reasons which exclude the confederation, the pact with the Crown and the right to self-determination as viable options. As an alternative, the author proposes the autonomic State, a still-unfinished original model which would not be the same as the Federal (with which there is no point maintaining a radical distinction), or the regional. The autonomic State would provide a solution to the Spanish territorial problem, since its flexibility and other features provide better for a certain degree of territorial asymmetry and a "balanced integration between such asymmetry and the necessary union of the State". The article conscientiously analyzes both theoretical questions and the procedure of constitutional reform which could result in the complete adoption of an autonomic State in Spain. 
I. SOBRE EL TRATAMIENTO DADO POR LA DOCTRINA ESPAÑOLA Y LA IMPORTANCIA DE UN LIBRO RECIENTE SOBRE LA MATERIA

\section{El entendimiento "constitucional” de la organización territorial del Estado}

Nuestro Estado autonómico ha sido objeto, como es lógico, de una multitud de estudios jurídicos, tanto de tipo general — desde el pionero y excelente libro de Santiago Muñoz Machado, Derecho público de las comunidades autónomas - como dedicados singularmente a cualquiera de sus muchos aspectos, desde los realizados de modo magistral por Eduardo García de Enterría, Ignacio de Otto o Gumersindo Trujillo, por ejemplo, hasta el importante y reciente libro de César Aguado sobre los estatutos de autonomía. Esa profusión de estudios no significa, ni mucho menos, que todos los problemas del Estado autonómico estén examinados o, mejor dicho, bien examinados; tampoco que lo hayan sido desde todas las perspectivas. Por ello siempre habrá necesidad de nuevos trabajos en la materia, aparte de que, como ésta es mudable, la continuidad de su estudio resulta, incluso, una consecuencia, podríamos decir que "natural".

Por lo que se refiere a la pespectiva o enfoque con que se han hecho los estudios sobre la organización territorial del Estado, predominan los realizados desde el punto de vista del derecho administrativo. Ha habido, claro está, buenos trabajos de derecho constitucional sobre la materia, pero no muchos. Entiéndase bien, me refiero a la comprensión de la autonomía territorial como un asunto eminentemente "constitucional", no a la profesión académica de los autores, que puede haber, y de hecho los ha habido, trabajos "constitucionales" hechos por administrativistas y trabajos "administrativos" hechos por constitucionalistas. De lo que estoy hablando es de una perspectiva mediante la cual la parte nuclear del derecho público autonómico se conciba y se practique como auténtico derecho constitucional autonómico. Un enfoque así resulta imprescindible porque es, me parece, el único que puede intentar explicar, y por ello ayudar a resolver, los problemas que en materia de autonomía política territorial nuestro Estado tiene planteados.

Ese ha sido siempre el enfoque de todos los trabajos del profesor Solozábal y específicamente de los ahora recogidos en su reciente libro 
sobre el Estado autonómico. ${ }^{2}$ El lector puede encontrar así, en las páginas de esa obra, desde estudios de derecho constitucional comparado, como el dedicado a los casos de Canadá y Suiza — donde tan rigurosamente se analizan los problemas que el nacionalismo y la diferenciación lingüística plantean al federalismo y en general a los Estados territorialmente compuestos - hasta estudios penetrantes como pocos de instituciones concretas (por ejemplo, los dedicados al Senado), a su significado, funciones, propuestas de reforma y correcto entendimiento de la representación territorial.

No es el caso detallar todo el contenido del libro: una mirada al índice basta para comprobar que los principales asuntos sobre nuestro Estado autonómico se encuentran allí atendidos. En unas ocasiones el estudio está hecho con amplitud. Así, los relativos al Senado, a los casos canadiense y suizo o a la automía vasca. En otras, el estudio es más conciso, aunque no menos valioso, así los trabajos sobre el sistema de fuentes en el Estado autonómico, sobre el reparto competencial o sobre la integración europea.

De todos modos, lo que caracteriza verdaderamente a este libro es algo que está expreso en su mismo título ("las bases constitucionales del Estado autonómico"), es decir, que es una obra sobre los principios y fundamentos constitucionales de la forma territorial de nuestro Estado y que, como se da a entender por el propio autor en el Prólogo, aunque expresamente así no lo diga, ese enfoque es el más adecuado para comprender los problemas de nuestra ordenación territorial. Se trata de una posición con la que estoy, por lo que antes dije, enteramente de acuerdo.

Todos los trabajos que integran el libro están realizados desde una doble convicción, y eso sí que lo deja patente Solozábal en el Prólogo: de un lado, que nuestro Estado actual, en su organización territorial, descansa en unas bases que suministra la propia Constitución, de manera que el llamado "desarrollo autonómico" de ellas ha de partir y a ellas ha de ser fiel, y de otro que, producto de esas bases y de su desarrollo, tenemos un tipo de Estado bien determinado, el Estado autonómico, que, aunque pertenece al género del Estado compuesto, posee unos rasgos bien singularizados.

2 Solozábal Echavarría, Juan José, Las bases constitucionales del Estado autonómico, Madrid, MacGraw-Hill, 1998. 
Esa doble convicción no es producto, ni mucho menos, de un acto de fe, sino de un examen, bien razonado, de los principios nucleares de nuestra organización territorial. Examen que se hace a lo largo de todo el libro, por supuesto, pero que tiene lo que podríamos llamar su representación principal en los trabajos "Los rasgos constitucionales del Estado compuesto", "Nación, nacionalidades y autonomías en la Constitución de 1978”, "El Estado autonómico como Estado nacional” y "Los principios de igualdad y simetría en el debate constitucional sobre el Estado autonómico".

\section{El entendimiento "institucional" del derecho constitucional}

Otra característica de este libro hay que subrayar: que está hecho desde un entendimiento del derecho constitucional como una disciplina (jurídica, claro está, eso no habría ni que decirlo) sin olvidar ni su carácter eminentemente práctico ni su necesario signo histórico ni su relación con la sociología o la ciencia política. El término "sensibilidad" — que tan mal suele emplearse hoy, sobre todo por políticos y periodistas- puede servir, en su sentido más correcto, para definir esa forma de practicar el derecho constitucional que distingue (en todos los sentidos) al profesor Solozábal. Un derecho constitucional que, sin merma de su rigor jurídico, es sensible a la naturaleza real de los problemas que con ese derecho han de abordarse.

El autor, en el Prólogo, lo confiesa cuando habla de su "sensibilidad respecto del entorno cultural y teórico en que se inserta necesariamente nuestro derecho constitucional". Y se trata, desde luego, de un enfoque consciente (y no sólo del resultado de una afición), por ello también se dice en el Prólogo que se parte de un entendimiento

institucional del derecho constitucional... de un planteamiento que no excluye la consideración del plano normativo desde otras perspectivas, de modo que el derecho constitucional se contamina o enriquece en virtud de su apertura a espacios o contextos culturales o espirituales en los está verdaderamente integrado, de los que recibe estímulos y solicitaciones y sobre los que también puede influir.

Por su contenido, pero sobre todo por su enfoque, el libro de Juan José Solozábal es, sin duda, una de las obras principales que en España se han 
producido sobre la forma territorial de nuestro Estado. La doctrina española sobre la materia se ha venido enriqueciendo, sin duda, a medida que fueron apareciendo los trabajos ahora recogidos en este libro, pero ahora ese enriquecimiento aumenta en la medida en que se hace más fácil (por su publicación unitaria) el acceso a tales trabajos, ofrecidos, además, con un Prólogo notable, lleno de cordura y expresivo de una muy correcta comprensión de lo que el derecho constitucional debe ser.

Precisamente por la importancia de este libro, y también por mi comunidad de ideas con el autor (algo que no debo en modo alguno silenciar) he querido situar el comentario de esta obra en la primera parte del presente trabajo dedicado a los problemas actuales de nuestro Estado autonómico. Este libro puede explicar muy bien el sentido de lo que ahora voy a decir. Por ello he querido enmarcar en él la exposición que sigue. Alrededor, pues, de las mismas preocupaciones expresadas por Solozábal y con puntos de vista sustancialmente parecidos a los suyos voy a extenderme ahora ofreciendo mis propias reflexiones (algunas ya adelantadas en anteriores trabajos míos) sobre el significado y la capacidad de supervivencia del Estado autonómico, en unos momentos, como los de ahora, en que tanto se habla de la necesidad de completarlo o incluso de cambiarlo.

\section{SOBRE LA SITUACIÓN ACTUAL DEL ESTADO AUTONÓMICO. ALTERNATIVAS Y LÍMITES PARA COMPLETAR EL MODELO DE ESTADO}

\section{Advertencia previa}

Con la vista puesta en la negociación sobre la integración territorial que parece avecinarse, las páginas que siguen tienen como pretensión reflexionar sobre la necesidad de aclarar el modelo territorial de nuestro Estado, para lo que resulta oportuno tanto señalar sus problemas actuales como proponer sus posibles soluciones. Requisito para lo segundo es, sin duda, tener una idea, no detallada, pero sí básica, de cuál debe ser el modelo resultante más adecuado. Sin saber el lugar de destino (o tener claro el horizonte) es muy difícil caminar con provecho, es decir, llegar a buen puerto. También es muy difícil (por no decir temerario) negociar sin saber lo que se puede y no se puede aceptar. 
No me importa (al contrario, creo que es necesario) subrayar que las reflexiones que ahora van a realizarse no sólo están sustentadas en razones de derecho constitucional, sino también de política constitucional. Pero en la medida en que estas segundas razones intentan sostenerse (ya se trate de propuestas de Constitutione ferenda, o de simples advertencias) en el terreno (me parece que sólido) que proporciona la teoría del Estado constitucional, no creo entonces que produzcan una "contaminación" perniciosa para el derecho constitucional, sino quizás un sano mestizaje. Me parece que en estos momentos un enfoque así puede ser adecuado para entrar a debatir los problemas reales que subsisten en la estructura territorial de nuestro Estado constitucional y democrático de derecho.

A tratar de todo ello están destinadas, pues, estas reflexiones, que no se proponen (sería una ligereza) entrar en muchos detalles a la hora de señalar soluciones y dibujar los contornos de aquel modelo territorial resultante, sino que sólo pretenden apuntar cuáles pueden ser las bases de tales soluciones y las línea maestras de dicho modelo.

\section{Límites (opciones que, técnicamente, no sería posible atender)}

Parece que para introducir una mínima e inexcusable claridad en un problema como éste, donde tanto espacio gana a veces la confusión, es conveniente comenzar por una delimitación negativa del problema, es decir, por establecer cuáles son sus fronteras. Se trata, pues, de excluir determinadas opciones sobre las que no cabría la negociación, simplemente porque no vendrían a significar el mantenimiento (con otra forma) de nuestro Estado, sino su disolución.

En ese sentido hay que advertir que estas páginas se escriben a partir de una base, que también conviene dejar clara: la permanencia del Estado español con su actual extensión territorial. De ese presupuesto se parte. Cuestión distinta es que, en una hipotética situación de extrema gravedad, pudiera considerarse como solución (o mal menor) la separación de parte del territorio. Una opción así sólo podría ser valorada atendiendo a razones exclusivamente políticas, que deben excluirse de las presentes reflexiones, sustentadas (incluso las dedicadas a propuestas de Constitutione ferenda) sólo en argumentos de naturaleza jurídico-técnica, o si se quiere, con más propiedad, jurídico-teórica. 


\section{A. La confederación o el pacto con la Corona}

Pocas líneas habría que emplear para excluir esta opción. Hoy no hay Estado que pueda organizarse bajo la forma confederal, sencillamente porque se trataría (como bien se sabe, puesto que ello es lo propio de la confederación) de una unión territorial de naturaleza más internacional que constitucional, incapacitada por eso para actuar (interna y externamente) con la mínima unidad de dirección y acción que hoy todo Estado requiere. Por supuesto que un hipotético Estado confederal no estaría en condiciones (por faltarle esa necesaria unidad de dirección y acción) de cumplir con las responsabilidades que supone pertener a la Unión Europea. Unión Europea, por cierto, cuyo grado de cohesión y cuyo ámbito de competencias superan con mucho la forma confederal (aunque aún no sea una federación).

De todos modos, como algunos partidos nacionalistas han propugnado, de manera tan profusa como difusa, la confederación como forma estatal para España, parece conveniente extenderse algo sobre este asunto (aunque ello suponga subrayar lo obvio). En realidad, la confederación sólo pudo existir en el pasado: en las colonias inglesas de Norteamérica que iban accediendo a su independencia, entre 1776 y 1787, y en Suiza, desde la Paz de Westfalia de 1648 (fecha de nacimiento de Suiza como Estado independiente) a la Constitución de 1848. No ha habido más casos de confederación. En el ejemplo norteamericano la confederación fue efímera y muy pronto, con la Constitución de 1787, se estableció una federación. En el ejemplo suizo la Constitución de 1848 (y con mayor claridad aún la de 1874) convirtieron la confederación en federación, aunque todavía siga llamándose Confederación Helvética, lo que (al margen de la semántica) jurídicamente es, sin duda, el Estado federal suizo.

Es dudoso incluso que el Estado pueda existir, como tal, esto es, como Estado, bajo una forma confederal. Pero es que, además, los términos "Constitución" y "confederacion" resultan contradictorios. Precisamente por ello ni siquiera hubo una "Constitución confederal norteamericana", sino un documento de tipo convencional, esto es, un pacto internacional, al que se le denominó "Artículos" de la confederación (la Constitución con la que surgió el Estado compuesto, es decir, los "Estados Unidos", fue la primera y única hasta ahora Constitución de la nación norteamericana, la federal de 1787). Y en el caso de Suiza, la única "Constitu- 
ción" de todo el territorio anterior a la de 1848 fue la impuesta por Francia en 1798 (que evidentemente no puede ser considerada una Constitución confederal, producto, pues, del pacto entre diversos territorios soberanos).

Puede decirse, pues, que no ha habido nunca "Constituciones confederales". Y ello es lógico, puesto que si discutible es que pueda existir el Estado bajo una forma confederal, indiscutible es que no puede existir bajo esa forma el "Estado constitucional", que basa su existencia en la soberanía nacional, y por lo mismo (ya sea el Estado unitario o federal) en la indivisibilidad de esa soberanía. Por lo demás, aparte de las razones teóricas, razones de orden práctico hacían incompatible la confederación con el tipo de Estados que existen a partir del siglo XIX (necesitados de mayor unidad de dirección y mayores competencias de actuación, tanto en el plano interno como en el internacional, que en ninguna otra época del pasado). La confederación pertenece, pues, a la historia y no al presente, y tampoco parece que pueda pertenecer al futuro en un mundo que camina cada vez más hacia la globalización.

Todo lo que acaba de decirse para la confederación vale para otra propuesta que a veces también se ha hecho: la de organizar el Estado español mediante una unión basada exclusivamente en la sujeción a la Corona. Eso, que técnicamente se conoce como "unión real", es incompatible con la existencia no ya sólo del Estado constitucional, sino simplemente de "un" Estado. García-Pelayo, que ya afirmaba (como cualquier autor solvente de derecho constitucional) que la confederación era una asociación puramente internacional y que los ejemplos históricos de confederación fueron "formas políticas imprecisas y transitorias destinadas, bien a disolverse, bien a transformarse en Estado federal", era más tajante aún (también como cualquier constitutionalista solvente) respecto de la "unión real" al aclarar que en ella no hay, ni puede haber, un sólo Estado, sino una pluralidad de "Estados independientes cuya soberanía no se encuentra afectada por el hecho del pacto" (del pacto con la Corona o del pacto entre Coronas). ${ }^{3}$

3 Se cita del Derecho constitucional comparado, últ. ed., Madrid, Alianza Editorial, 1984, pp. 209-210 y 207 , respectivamente. 


\section{B. El derecho de autodeterminación}

La primera precisión que cabe hacer respecto de este asunto es que, como tal derecho, esto es, reconocido por el ordenamiento, el derecho de autodeterminación sólo existe en el plano internacional, siendo sus titulares las comunidades sometidas a un régimen colonial. Es evidente que en España (en cuyo seno no cabe, bajo ningún aspecto, considerar que exista cualquier colonia) ninguna comunidad autónoma, o más ampliamente, ninguna comunidad territorial infraestatal, puede considerarse titular de ese derecho.

Cosa bien distinta es la apelación a tal derecho no como un derecho "jurídico", sino como un derecho "natural", "moral" o "histórico". En tal caso se está en presencia, en realidad, no de un verdadero derecho (que sólo "jurídico" puede ser) sino de una pretensión estrictamente política, que sólo es formulable (en rigor) como propuesta de futuro, esto es, de Constitutione ferenda, pero nunca de Constitutione lata. En nuestro ordenamiento, como en cualquier ordenamiento jurídico, no hay "derechos naturales", sino sólo "derechos positivos". La moral, por lo demás, no es fuente del derecho. Y los "derechos históricos", que la Constitución "ampara y respeta", sólo pueden considerarse vigentes "en el marco de la Constitución y de los estatutos de autonomía" (como dice expresamente la disposición adicional primera de la misma Constitución), es decir, siempre que no contradigan el propio ordenamiento constitucional.

Aparte de que difícilmente puede encontrarse entre los "derechos históricos" de los territorios forales el de "autodeterminación" (según tienen probado las investigaciones históricas más solventes), lo que resulta perfectamente claro es que tal derecho (cuyo hipotético titular no sería, por lo demás, la comunidad autónoma del País Vasco, sino individual y singularizadamente cada uno de los territorios históricos de Vizcaya, Guipúzcoa y Alava, así como la comunidad foral de Navarra) no estaría en vigor por no caber en el "marco constitucional", en cuanto que la Constitución sólo atribuye el "derecho de autodeterminación" (esto es, el derecho a decidir libremente, o lo que es igual, soberanamente, sobre su forma política) al pueblo español en su conjunto (artículo 1.2).

Para que tal derecho existiese, atribuido a un sector del actual pueblo español (y no a todo ese pueblo) tendría que reconocerlo así, expresamente, la propia Constitución, es decir, se haría precisa una reforma 
constitucional. Y aquí surge un problema de extraordinaria complejidad. La primera complejidad, aunque no la mayor, reside en el procedimiento de reforma constitucional para introducir tal derecho: habría de ser, indiscutiblemente, el previsto en el artículo 168 de la Constitución, en cuanto que afectaría al artículo 1.2 del propio texto constitucional. Se trata, como es bien sabido, de un procedimiento extraordinariamente rígido, que exige la mayoría de dos tercios en el Congreso y en el Senado, la celebración de unas inmediatas elecciones generales, la ratificación por las nuevas cámaras del proyecto de reforma elaborado por las anteriores cámaras y su discusión y aprobación nuevamente por mayoría de dos tercios en el Congreso y en el Senado, así como la aprobación final de la reforma por referéndum (preceptivo) de todos los españoles. No habría otra forma ( $\mathrm{si}$ es que quiere respetarse, pues, el ordenamiento constitucional vigente) de establecer el derecho de autodeterminación.

El problema más complejo, de todos modos no es ese, sino el que deriva de la incompatibilidad, radical, de ese derecho con el concepto mismo de Constitución y de Estado constitucional. La unidad del ordenamiento no es que sea un límite implícito a cualquier reforma de la Constitución, sino que es un requisito o presupuesto de la misma. Por ello, si puede defenderse (esa es mi opinión, aunque sé que es discutible) que mediante la reforma por la vía del artículo 168 puede el pueblo español autodisponer de sí mismo y por ello acordar la separación de parte de ese pueblo, no puede, en cambio, atribuir a otro titular que no sea él ese derecho a la separación (mejor dicho, a la autoconfiguración o autodelimitación poblacional y territorial del propio soberano). Como muy bien decía Kelsen, el derecho no puede sustentarse en el postulado de "debes si quieres", sencillamente porque entonces el derecho se disolvería.

Al margen de razones políticas (que hacen muy difícil, por no decir prácticamente imposible, que un Estado pueda operar con eficacia en el plano interno y sobre todo en el plano internacional si la composición y estructura de ese Estado en lugar de estar garantizadas, esto es, predeterminadas, quedan a la libre y permanente aquiescencia de cualquiera de sus partes), hay razones teóricas que impiden que un ordenamiento pueda garantizar el derecho de autodeterminación a una entidad distinta que no sea todo el pueblo del que ese ordenamiento emana. Dicho en otras palabras, de lo que se trata es de la unidad (y por ello indivisibilidad) de 
la soberanía como requisito de existencia del propio Estado. En el fondo las razones que más atrás se dieron para mostrar la improcedencia de la confederación son las mismas que cabe aducir para mostrar la improcedencia del derecho de autodeterminación. En realidad, Constitución y derecho de autodeterminación (siempre referido a parte de la población del Estado) son términos excluyentes. La reciente sentencia del Tribunal Supremo del Canadá lo ha puesto bien de manifiesto. Por ello, ni siquiera a través de la reforma constitucional podría introducirse en nuestro ordenamiento el derecho de autodeterminación conferido a cualquier parte de la población española.

\section{Alternativas}

\section{A. ¿Estado federal o Estado autonómico?}

Aunque la Constitución no definía el modelo territorial del Estado, sino que lo dejaba abierto, los sucesivos estatutos de autonomía y la jurisprudencia del Tribunal Constitucional han ido configurando un modelo, aún inacabado, que no es exactamente el de un Estado federal, pero tampoco el de un Estado regional (forma esta última que carece, por cierto, de rasgos definidos, pues los únicos ejemplos de ella, el español de la 2a. República, el italiano actual, el belga de 1970 a 1994 y el portugués vigente desde 1976 tienen muy poco en común). El modelo de Estado que en España, desde la transición política (los regímenes "provisionales" de autonomía se adelantaron a la propia Constitución), se ha venido construyendo resulta, pues, bastante original y ya es un uso aceptado llamarle "Estado autonómico".

Por muchas razones, carece hoy de sentido sostener una distinción radical entre Estado federal y Estado autonómico. La propia denominación constitucional del tipo de Estado no es estrictamente necesaria: un Estado puede ser federal aunque su Constitución no lo diga (como ocurre con el ejemplo más canónico, el de los Estados Unidos de América) y, por el contrario, si se parte de los rasgos clásicos mínimamente indicativos del federalismo, puede haber un Estado que sólo tenga de federal el nombre, como ocurre y, sobre todo, ha ocurrido en algunos Estados iberoamericanos y como sucede, en un caso ya en el territorio europeo, con el Estado belga, al que la nueva Constitución de 1994 denomina "federal" sin que se parezca en nada a los demás modelos de federalismo 
que hoy existen. Y en cuanto al Estado regional, no aparece así llamado ni en la Constitución portuguesa ni en la italiana, ni tampoco era denominado así en el texto de la belga anterior a 1994, ni en el de la española de 1931 (que hablaba de Estado "integral”, pero no de Estado "regional"). Tampoco la española actual llama a su Estado "autonómico" (ni de ninguna otra manera, desde el punto de vista territorial).

Hoy no son rasgos necesarios del federalismo ni la soberanía compartida, como ha dejado bien claro la doctrina moderna (que habla de federalismo "cooperativo" o de Estado federal "unitario" y rechaza que pueda haber Estado sin unidad de la soberanía), ni la existencia de un Senado o segunda Cámara federal con representación igualitaria de todos los Estados miembros (igualdad que se da en los Estados Unidos de América y en México —o Estados Unidos Mexicanos-, por ejemplo, pero no en Alemania o Austria), ni que ese Senado sea elegido por la población de los Estados (esa elección existe en México y en los Estados Unidos, por seguir con el mismo ejemplo anterior, pero no en Austria, donde son elegidos por los parlamentos regionales, ni en Alemania, donde son los ejecutivos territoriales los representados en el Bundesrat), ni siquiera la existencia de la dualidad estatal ("Estado" federal y "Estados" miembros), ya que tanto en Alemania como en Austria los componentes de la federación no son "Estados" (el único "Estado" así llamado es el federal) sino "länder" (países) y en Argentina el contraste es aún mayor: las entidades federadas son las "provincias".

En definitiva, no hay, pues, un sólo modelo de Estado federal, ya que entre los Estados federales —norteamericano, alemán, argentino o belga, por poner varios ejemplos- puede haber más diferencias que entre cualquiera de ellos y el Estado español actual. Por otra parte, el grado de autonomía (y por ello de competencias) de las entidades territoriales que integran los Estados federales es muy distinto según el Estado federal de que se trate y puede darse el caso, además, de que en un Estado no federal, como es el autonómico español, las comunidades autónomas posean muchas más competencias de las que tienen los Estados miembros de las federaciones. Por ejemplo, el grado de autonomía del País Vasco es muy superior al de la inmensa mayoría de los Estados o países miembros de cualquier Estado federal.

A partir de todo lo anterior no parece, en consecuencia, que para afrontar los problemas de integración territorial que aún subsisten en 
España sea adecuado apoyarse en la distinción entre Estado federal y Estado autonómico pensando que el primero, por sí solo, puede significar un mayor paso hacia la descentralización y un mejor modo de organización de las autonomías territoriales. No es descartable que un cierto tipo (no hay un modelo único) de Estado federal pueda proporcionar en España una mayor racionalización del modelo descentralizador, pero tampoco es descartable que lo que pudiera conseguirse por el lado de la eficacia se perdiese por el lado de la integración territorial. Nuestro problema de integración territorial, que no es otro que el de la existencia de fuertes nacionalismos en ciertos lugares del territorio, no permite planteamientos simples ni soluciones radicales. Tampoco permite, por supuesto, que se siga viviendo muchos más años en la ambigüedad sin aclarar suficientemente el tipo de Estado que tenemos, o que queremos.

\section{B. Hacia un modelo territorial de integración}

A la hora de reflexionar sobre la estructura territorial del Estado no conviene olvidar que la Constitución no reconoció (artículo 2o.) el derecho a la autonomía de las "nacionalidades y regiones" porque hubiese que resolver un problema de integración de las regiones, sino porque ese problema donde existía era en las "nacionalidades". Después, el desarrollo autonómico, orientado desde un entendimiento más administrativista que constitucionalista de la estructura territorial del Estado, hizo tabla rasa de la distinción expresada en el artículo 20. de la Constitución, extendió el término "nacionalidades" a otras comunidades distintas de Cataluña, el País Vasco y Galicia (que eran las únicas a las que, por consideraciones históricas, la Constitución, en su disposición transitoria segunda, atribuía el privilegio de acceso, sin referéndum previo, al máximo nivel de autonomía) y se decantó por un sistema de generalización territorial autonómica, paridad de nivel de autonomía y sustancial igualación competencial (salvo en materia fiscal, en los casos del País Vasco y Navarra).

Este sistema, que ha venido sosteniendo la situación hasta hoy, no parece que haya de tomarse como el definitivo. De un lado, porque ni siquiera está acabado (falta, entre otras cosas, la pieza del Senado territorial), y de otro porque aún no ha conseguido integrar con éxito, es decir, plenamente, al menos a dos partes muy significativas del territorio del Estado: el País Vasco y Cataluña. España sigue teniendo un grave pro- 
blema de articulación territorial, no de tipo administrativo (donde también existen problemas, pero que son de menor calado en cuanto que sólo pueden provocar crisis de eficacia), sino de tipo político o constitucional, esto es, un problema de identidad, que es el que puede provocar una crisis de convivencia. Ningún Estado compuesto puede soportar sin grave quebranto para su subsistencia que en cada elección autonómica se ponga en juego la propia estructura territorial estatal, es decir, que en lugar de entrar en la contienda electoral, periódicamente, distintos programas de gobierno, lo que entren en liza periódicamente sean distintas concepciones del Estado. Dicho de manera más directa, un Estado tiene muchas dificultades para sobrevivir si en partes de su territorio se está poniendo en cuestión permanentemente (por la mayoría política, o por un sector sustancial de la población) su pertenencia a la comunidad nacional.

Parece necesario, pues, abordar de manera definitiva el modelo territorial del Estado (empleando el término "definitiva" no en su sentido fuerte, como solución inapelable o cerrada, sino en su sentido flexible, como solución que vendría a terminar de "definir" o "aclarar" el sistema y por ello a "resolver" el problema en sus rasgos básicos). Y esa decisión "concretadora" o de terminación del proceso autonómico, que aún se encuentra inacabado, ha de tomar como objetivo (no puede ser otro) la integración territorial. Valdrá, pues, en la medida en que consiga la adhesión de todas las comunidades autónomas (y especialmente de aquellas donde ahora la integración es problemática). La transición a la democracia se culminó hace ya bastante tiempo. La transición a la autonomía todavía está sin acabar y es cada vez más urgente culminarla. Esa es, parece, la perspectiva adecuada para enfrentarse con los problemas de nuestro modelo territorial del Estado.

\section{C. ¿Igualdad o asimetría?}

Lo primero que debe aclararse al tratar esta cuestión, sin duda una de las principales en el problema que nos ocupa, es el distinto significado de algunos términos que muchas veces se usan como sinómimos y otras se utilizan de manera bastante confusa. Una cosa es la igualdad competencial y otra bien distinta la diferencia entre comunidades. Aunque tengan las mismas competencias, o más correctamente, el mismo nivel de competencias, no por ello las comunidades autónomas han de ser uniformes. Por una parte, características "estructurales" (lengua distinta, dis- 
tinta situación del territorio, etcétera) de cada comunidad pueden $-\mathrm{y}$ a veces "tienen" que- dar lugar a diferencias competenciales sin que ello sea producto de una deliberada desigualdad competencial. Por otra parte, el distinto modo de "ejercitar" las mismas competencias también puede ocasionar manifiestas diferencias del régimen jurídico entre unas y otras comunidades autónomas (un buen ejemplo de esa "diversidad" entre Estados miembros de la federación lo proporciona el caso norteamericano).

También una cosa es la igualdad competencial y otra bien distinta la igualdad de posición. Es posible que pudiese haber una igualdad en el nivel de competencias entre todas las comunidades autónomas, pero ello no quiere decir que, necesariamente, todas esas comunidades hayan de tener el mismo "peso" en la estructura estatal. Así, distinta puede ser la participación de las comunidades en el Senado, en la formación de la política estatal europea, e incluso en la designación de miembros de órganos constitucionales o en la propia reforma constitucional. En un Estado compuesto puede haber asimetría no sólo porque haya desigualdades competenciales, sino también porque haya desigualdes de estatus o posición entre los distintos territorios.

Por último, una cosa es la uniformidad y otra la homogeneidad. Es muy probable que una estructura estatal territorialmente heterogénea sea muy poco eficaz, y es muy probable también que tampoco fuera hoy aceptada por "todas" las comunidades autónomas, pues la mayoría de ellas no parece que admitiesen una distinción entre comunidades de primera y de segunda, o de grado superior e inferior, o de autonomía política y autonomía administrativa. Sobre ello parece que ya no cabe marcha atrás. Ahora bien, la homogeneidad no significa necesariamente uniformidad. Puede haber (como hay actualmente) homogeneidad autonómica, pues todas las comunidades, a excepción de los casos de Ceuta y Melilla, donde el grado de autonomía es inferior, tienen el mismo tipo de autonomía política: autogobierno y autolegislación; con una base común de títulos competenciales (después de los últimos pactos autonómicos): la derivada tanto del artículo 148 como del artículo 149 de la Constitución. Sin embargo, ello es compatible con una diversidad no sólo cuantitativa, sino cualitativa. Cuantitativa sería la derivada de las diferenciaciones a que más atrás se ha hecho alusión. Cualitativa sería la derivada de los "hechos diferenciales" que la misma Constitución ha señalado. 
A partir de la homogeneidad y de la no discriminación de los ciudadanos por motivos territoriales (no discriminación que la Constitución garantiza en sus artículos 14, 138.2, 139.1 y 149.1.1a., y que todo Estado compuesto, sea del tipo que sea, si es Estado constitucional democrático y de derecho ha de garantizar), parece que el único modo de integrar lo diverso (puesto que en España hay diversidades territoriales con relevancia política) es organizar el Estado introduciendo algunos ingredientes de asimetría.

En mi opinión, el Estado federal, pese a las diferencias tipológicas que se dan en su seno, no parece un modelo apropiado para soluciones territorialmente asimétricas. Lo propio del federalismo es la igualdad competencial (que es algo distinto de la "diferencia" competencial, como ya se dijo) y la sustancial igualdad de posición constitucional de los territorios que lo componen. Es cierto que no cabría descartar de plano, aunque sea en teoría, la hipótesis de un federalismo asimétrico, pero la experiencia de los federalismos que funcionan no camina en ese sentido. Por ello, desde ese punto de vista, el Estado autonómico, por su mayor flexibilidad y originalidad, puede resultar, me parece, un modelo mejor para albergar la asimetría territorial que el Estado federal.

De todos modos, el problema no debe quedar reducido a un dilema de denominaciones, porque, como ya vimos, federalismos puede haber de muchas clases e incluso el Estado federal puede existir sin que la propia Constitución lo denomine así. Como bien se sabe, lo importante es la cosa en sí no el nombre que se le dé. De lo que se trata entonces es de determinar el contenido de la asimetría (necesaria para la plena integración de ciertas partes del territorio español) que resultaría compatible con aquella homogeneidad a la que antes me he referido (homogeneidad necesaria para la actuación eficaz del Estado y a la que difícilmente renunciarían la mayoría de las comunidades autónomas).

Parece que esa asimetría puede ser de dos tipos: competencial y estructural.

\section{Asimetría competencial}

Parte de esa asimetría ya está aceptada y experimentada: los conciertos económicos, que sólo corresponden al País Vasco y Navarra, así como la existencia de Policía propia, que podría quedar reducida, quizás, al ámbito de las comunidades autónomas que ya la tienen (por el Estatuto 
o por Ley Orgánica del Artículo 150.2 de la Constitución). Es cierto que la asimetría competencial podría ampliarse mediante la utilización futura de las leyes orgánicas de delegación y transferencia previstas en el artículo 150.2 de la Constitución. De todos modos, no parece que sea aquí donde pueda haber una asimetría significativa, entre otras razones porque pocas competencias más pueden ya transferirse sin que se ponga en riesgo la unidad de acción y dirección estatal y la misma responsabilidad del Estado ante la Unión Europea.

\section{E. Asimetría estructural}

Quizá sea en la asimetría estructural donde más espacio haya para una asimetría "significativa", esto es, para una asimetría que fomente la integración de las "nacionalidades" con fuerte "nacionalismo". Justamente porque esta asimetría afecta a la posición o estatus es por lo que tiene una mayor carga simbólica, que es en el fondo de lo que se trata, fundamentalmente, cuando se abordan problemas de integración territorial.

En ese sentido, y sólo a título de ejemplo (pues entrar en mayores detalles excedería del objeto de las presentes reflexiones), voy a referirme a algunas "posibles" asimetrías estructurales.

Así, cabría organizar un Senado en el que no sólo las distintas comunidades autónomas tuviesen una representación proporcional a su población, sino en el que también se atribuyese (bien mediante el establecimiento de un tipo de mayorías cualificadas para determinados asuntos o bien mediante un sistema de vetos) un peso específico singular a Cataluña, País Vasco y Galicia, así como a las demás comunidades autónomas con lengua propia en asuntos relacionados con la educación y la cultura. Ello obligaría a un funcionamiento complejo del Senado, que habría de organizarse no sólo mediante grupos parlamentarios "partidistas" sino también mediante grupos parlamentarios "territoriales".

También cabría atribuir una especial participación a los gobiernos de dichas comunidades autónomas en la realización por el gobierno estatal de la política comunitaria europea en materias afectadas por los "hechos diferenciales" constitucionalmente reconocidos.

Posiblemente una de las asimetrías más significativas y de mayor capacidad de integrar a los nacionalismos sea la de asegurar una determinada participación (y al mismo tiempo una especie de veto otorgado a una minoría) de las comunidades autónomas en la "aprobación" (ahora 
sólo pueden participar en la "iniciativa") de la reforma constitucional (es decir, asegurarles la participación en el poder constituyente-constituido). Pero no para todas las reformas constitucionales. Así, en las previstas en el artículo 168 de la Constitución, por afectar a las bases de la forma del Estado, no cabría dar participación a partes del territorio o a partes de la comunidad soberana, que es el pueblo español en su conjunto. Esa participación se limitaría a las reformas previstas en el artículo 167 de la Constitución, pero incluso ahí no a todas ellas, sino sólo a las que afectasen al título VIII de la propia Constitución. Para ello bastaría con exigir como otro requisito de tales reformas, aparte de los ya constitucionalmente establecidos, bien su aprobación por un determinado número (que habría de ser alto) de comunidades autónomas (de sus parlamentos), o bien que dentro de un determinado plazo tales reformas no fueran vetadas por un número mínimo (que habría de ser bajo) de dichas comunidades. El referéndum facultativo previsto en el citado artículo 167 sólo cabría celebrarlo si la reforma hubiera pasado con éxito el referido trámite de participación autonómica.

Esta participación tendría, como se ha dicho, una muy especial significación e iría mucho más allá de la hasta ahora prevista, que es sólo la participación de las comunidades autónomas en la "iniciativa" (mejor dicho, en la "propuesta" de iniciativa) de reforma constitucional (a tenor de lo que expresan los artículos 87.2 y 166 de la Constitución). Hacerlas participar también en la "aprobación" del texto de la reforma constitucional no es exactamente equiparable al derecho de autodeterminación, pero tiene (al menos simbólicamente, me parece) alguna relación con él.

Igualmente cabría pensar en otras asimetrías estructurales que ahora, como ya se ha dicho, no viene al caso detallar, siempre que las mismas, eso sí, no pusieran en peligro la estabilidad del Estado y su unidad de acción y dirección.

\section{Procedimiento para acabar de concretar el modelo territorial del Estado: la reforma constitucional}

Dado que ya, por unanimidad de las fuerzas políticas, se tiene decidido reformar el Senado y que ello sólo puede realizarse reformando la Constitución, no parece que tenga mucho sentido sostener que la construcción final del modelo de Estado no necesite de la reforma constitucional. Por 
ello, parece que aceptar la necesidad de reformar la Constitución puede ser una posición bastante razonable.

El contenido de la reforma cabe limitarlo, claro está, a la reorganización del Senado, pero también puede ir más allá si políticamente se estimase necesario en un proceso de negociación sobre la estructura territorial del Estado. Incluso podría aprovecharse también para introducir un nuevo título constitucional relativo a la Unión Europea, como han hecho las Constituciones de otros países. Este nuevo título resultaría oportuno no sólo para dar estatuto constitucional a la regulación de nuestra intregración europea (ahora muy precariamente normativizada en el artículo 93 de la Constitución) sino también para establecer (si así se quisiera) algún tipo de asimetría en la organización estatal autonómica en relación con esa materia. Atendiendo a ambos objetivos (integración europea e integración autonómica), esa hipotética reforma constitucional también podría afectar al título IV (sobre el gobierno y la administración) y al título VIII (sobre la organización territorial del Estado).

Para realizar esa reforma constitucional no sería preciso acudir al procedimiento del artículo 168 sino al más sencillo del artículo 167. De todos modos, esta reforma sólo sería eficaz para el objetivo que se pretende (la "definitiva" integración territorial española) si se realiza por consenso, es decir, por acuerdo entre todos los partidos políticos relevantes y entre todas las comunidades autónomas. En ese caso, además, aunque no sea preceptivo el referéndum sería muy conveniente celebrarlo, primero porque su éxito estaría asegurado y segundo porque así una reforma de tanta significación política como ésta recibiría directamente la legitimación popular.

Además de lo que acaba de exponerse, no quiero dejar de referirme a la posible asimetría ya aludida, relacionada con la participación de las comunidades autónomas en la reforma constitucional. El problema aquí es que si bien la Constitución no dice nada, hay que entender, por exigencias teóricas, que la reforma de las normas sobre la reforma de la Constitución (tanto si afecta a la reforma prevista en el artículo 167 como a la dispuesta en el artículo 168) está reservada al procedimiento de reforma más rígido, esto es, al determinado en el artículo 168 (por el procedimiento del artículo 167 no puede reformarse el artículo 167; eso, disponer de las reglas de la propia reforma constitucional, sólo puede hacerlo el "constituyente juridificado", que no es otro que el reflejado 
en el procedimiento del artículo 168). De quererse introducir esta participación de las comunidades autónomas habría necesariamente de acudirse a la muy difícil (desde el punto de vista jurídico) y muy problemática (desde el punto de vista político) reforma por la vía del artículo 168 de la Constitución.

\section{La denominación del modelo resultante}

Aunque se quisiera denominar expresamente este modelo como "federal" no parece necesario decirlo así en el título preliminar de la Constitución (lo que obligaría a seguir el difícll procedimiento de reforma del artículo 168) sino que bastaría con aludirlo en el título VIII. De todos modos, tampoco sería preciso constitucionalizar el "nombre" del modelo, pues de lo que se trata es de perfilarlo y dotarlo de contenido. Ya vendrá después la doctrina a denominarlo. Por lo demás, que se le llame Estado federal o Estado autonómico no es lo más decisivo ni para asegurar un mayor nivel de autonomía ni para logar un mayor nivel de integración.

En tal sentido, no está de más volver a insistir en que quizás el Estado autonómico posea mayores capacidades de integración (por su flexibilidad y originalidad) que el Estado federal. Además, la estructura constitucional del Estado autonómico, formada por el "bloque constitucional", que es un conjunto normativo integrado por la Constitución y los estatutos de autonomía (donde pueden diferenciarse dos niveles de normas constitucionales, primarias y secundarias, y donde se da una mezcla muy equilibrada de multilateralidad y bilateralidad), resulta bastante adecuada para articular un Estado, como el nuestro, en el que han de coexistir "nacionalidades" y "regiones" (en el sentido originario que la Constitución quiso darles). Por lo demás, en la definición del Estado autonómico ya se ha avanzado bastante por obra conjunta de los estatutos de autonomía y de la doctrina del Tribunal Constitucional. Parece, pues, que seguir por tal camino es menos costoso (y más seguro) que cambiar ahora de modelo. En este terreno, optar por la "concretización" o desarrollo de la Constitución es preferible, creo, a iniciar un nuevo proceso constituyente. De todos modos, acerca del significado constitucional y de las capacidades del Estado autonómico, así como de la naturaleza de su ordenamiento constitucional, donde tan relevante función desempeñan los estatutos de 
autonomía, dada su específica singularidad normativa, no es preciso extenderse aquí porque lo he tratado en otros trabajos, ${ }^{4}$ a los que me remito.

\section{Una discusión inútil y una terminología perturbadora: "nación de naciones"}

La inutilidad de la discusión proviene de que la fórmula "nación de naciones" no puede servir de solución para nuestros problemas de integración territorial. Y ello es así porque si nación, en la segunda parte del término, significa nación política, entonces una nación de naciones requeriría un Estado plurinacional y por ello un Estado compuesto por entidades soberanas, es decir, un imposible. Y si nación, en la segunda parte de la fórmula, lo que significa es nación "cultural" (y no nación política) entonces, de una parte el término queda vacío de sentido "nacionalista" (en cuanto que el nacionalismo es inseparable del sentido político de nación) y de sentido jurídico-constitucional (para el que nación es la base popular del Estado, esto es, la titular de la soberanía), con lo cual lo que vendría a significar es exactamente "nacionalidad", que es, por cierto lo que dice nuestra Constitución en su artículo 2o.

En resumidas cuentas, si se propugna el término como algo distinto a lo que ahora la Constitución dice, su significado sería incompatible con la existencia del propio Estado, aunque sea un Estado compuesto, y si lo que el término significa es lo mismo (aunque con otras palabras) de lo que ahora dice la Constitución, no se ve por qué habría de cambiarse ésta (cuando resulta, además, que ese cambio, por afectar al título preliminar, habría de hacerse por el muy difícil y complicado procedimiento del artículo 168), ni introducirse en la Constitución una fórmula que encierra una verdadera contradicción y es germen, por ello, de disolución no sólo del texto constitucional sino incluso del propio Estado. Cuando se trata de las bases de la forma del Estado, y por ello de los principios nucleares organizadores de la convivencia ciudadana, las palabras no son inocentes, ni mucho menos.

4 "La reforma de los estatutos de autonomía” y "El Estado autonómico: ¿modelo indefinido o modelo inacabado?", ahora recogidos en mi libro Estudios de derecho constitucional, Madrid, Centro de Estudios Constitucionales, 1998. 
7. A modo de conclusión: la aclaración del modelo territorial del Estado y el procedimiento para llevarla a cabo

a) En cuanto al modelo territorial existirían (me parece, como soluciones "válidas") dos alternativas: la del Estado federal y la del Estado autonómico.

De acuerdo con lo que antes se ha dicho, parece que es preferible optar por el Estado autonómico por muy diversas razones: primera, porque ya lo estamos construyendo (y sería, pues, muy costoso abandonarlo); segunda, porque ya existe un alto grado de consolidación doctrinal y jurisprudencial sobre el mismo; tercera, porque el nivel de autonomía territorial que puede admitir es el mismo (e incluso superior) que cabría en un Estado federal, y cuarta, porque por su originalidad y flexibilidad puede permitir mejor que el Estado federal cierto grado de asimetría territorial y, lo que es más importante aún, una equilibrada integración entre dicha asimetría y la necesaria unidad estatal.

De lo que se trataría, entonces, es de "culminar" (y no de "abandonar" o "cambiar") el proceso ya iniciado desde la transición política y, sobre todo, desde 1978, en lo que se refiere a la organización territorial del Estado, con vistas a una plena integración política de todas sus comunidades. Esta estrategia de "evolución" es siempre más fructífera (en todos los terrenos) que las estrategias de "ruptura".

b) En cuanto al procedimiento existirían dos alternativas: con o sin reforma de la Constitución. La opción por no utilizar la reforma constitucional parece que habría que descartarla, al menos en lo que se refiere al Senado, ya que todos los grupos políticos ya han decidido que esa reforma constitucional sí va a realizarse. Por ello, las opciones reales son: o con una reforma constitucional reducida a la reorganización del Senado o con una reforma constitucional más amplia.

Como el Estado autonómico puede completar su desarrollo mediante la reforma de estatutos de autonomía y el empleo de las leyes previstas en el artículo 150 de la Constitución sin necesidad de reformas constitucionales salvo en lo que se refiere al Senado, esta opción sería quizás la menos costosa y problemática. No obstante, si políticamente se creyese oportuno (por exigencias de la negociación política territorial) aclarar y garantizar "constitucionalmente" (y no sólo "infraconstitucionalmente") el modelo territorial del Estado (algo que la Constitución dejó origina- 
riamente "abierto" o "inconcreto"), podría acudirse a una reforma constitucional más amplia, del tipo de la que más atrás se ha aludido. Reforma que debería realizarse siempre por el procedimiento (relativamente simple y sencillo) del artículo 167 de la Constitución, salvo que se quisiese reformar el propio artículo 167, en cuyo caso habría de acudirse al muy rígido y complicado procedimiento previsto en el artículo 168 de la Constitución.

c) En cuanto al sustento teórico del proceso a que nos estamos refiriendo hay dos posibles opciones: partir de un entendimiento de los problemas de nuestro Estado compuesto desde la perspectiva de un derecho público poco sensible a las cuestiones políticas, sociales y culturales de fondo que en ese Estado existen, o acometer el tratamiento de aquellos problemas desde la perspectiva de un derecho constitucional que, si merma de su solidez jurídico-teórica, sea sensible a tales cuestiones. Creo que la opción por lo segundo es clara y, en tal sentido, el libro del profesor Solozábal, a cuyo comentario he dedicado la primera parte de este trabajo, facilita para ello una herramienta intelectual extraordinariamente adecuada. 